\title{
Identification of Gram-negative non-fermenters and oxidase-positive fermenters by the Oxi/Ferm Tube
}

\author{
B. HOLMES, J. DOWLING, AND S. P. LAPAGE \\ From the National Collection of Type Cultures, Central Public Health Laboratory, Colindale, London \\ NW9 $5 H T, U K$
}

SUMMARY Since the recent introduction of the Roche Oxi/Ferm Tube to the UK two identification schemes have been developed by the manufacturer for use with the kit. We evaluated the success of these two schemes in identifying 222 predominantly culture collection strains belonging to 45 taxa of non-fermenters and nine taxa of oxidase-positive fermenters. The strains were chosen to represent all the taxa included in the two identification schemes developed by the manufacturer and we have therefore been able to assess the overall success of identification by the two schemes. Since, however, our choice of strains does not reflect their incidence in clinical material, our identification rates are not necessarily those that might be obtained in a routine clinical laboratory. The most advanced identification scheme so far developed for the Oxi/Ferm Tube (CCIS System 1977-1432) allowed $62 \%$ of the 222 strains to be correctly identified although a disturbing feature was that more of the strains that were not correctly identified were incorrectly identified $(24 \%)$ rather than not identified $(14 \%)$; these figures represent an improvement over the earlier identification scheme (CCIS System 1976-621-74346) for which the corresponding figures were $56 \%, 32 \%$, and $12 \%$. CCIS System 1977-1432 seems likely to give a better performance in a routine clinical laboratory than in this study since for those taxa which, we would judge from the material sent to us for identification, are most commonly seen in a routine laboratory (Acinetobacter calcoaceticus, A. lwoffi, Pseudomonas aeruginosa, $P$. fluorescens, $P$. maltophilia, $P$. pseudoalcaligenes, and $P$. putida) $89 \%$ were correctly identified, none remained unidentified, and $11 \%$ were incorrectly identified. Thirty strains, each of a different taxon, were tested in triplicate to assess the reproducibility of reactions in the Oxi/Ferm Tube.

The Oxi/Ferm Tube, a diagnostic kit designed for the identification of aerobic, Gram-negative, nonfermentative bacteria and of oxidase-positive fermentative bacteria, was initially introduced into the USA by the manufacturer of the Enterotube, a kit designed on similar principles for the identification of enterobacteria. Evaluations have been published (Freundlich et al., 1977; Isenberg and Sampson-Scherer, 1977; Kilbourn, 1977; Oberhofer et al., 1977a, 1977b; Nadler et al., 1978; Smith et al., 1978; Timm et al., 1978). The Oxi/Ferm Tube has been evaluated in parallel with the API 20E system, a kit designed primarily for enterobacteria, and modified for the identification of non-fermentative bacteria by the addition of six supplementary tests

Received for publication 1 September 1978
(Dowda, 1977; Nord et al., 1977; Rinehart and Oberhofer, 1978; Snyder et al., 1978). Other workers have evaluated the Oxi/Ferm Tube in parallel with the API 20E system and one or more other systems (Bannister et al., 1978; Otto et al., 1978). The evaluations of the various authors suggested that the Oxi/Ferm Tube was a useful product, the proportion of strains correctly identified ranging from $84 \%$ (Nadler et al., 1978) to $98 \%$ (Rinehart and Oberhofer, 1978). Misidentification rates were correspondingly low, for example, $4.5 \%$ (Dowda, 1977).

Isenberg and Sampson-Scherer (1977), McHale et al. (1978), Nadler et al. (1978), Smith et al. (1978), and Snyder et al. (1978) all found the reproducibility of the Oxi/Ferm Tube tests to be good in the main, although Smith et al. (1978) reported a poor reproducibility for the citrate test of the kit. Freundlich 
Table Identification of 242 strains by two different systems

\begin{tabular}{|c|c|c|c|c|c|c|c|c|}
\hline \multirow[t]{2}{*}{ Taxon } & \multirow[t]{2}{*}{ Strains examined } & \multirow{2}{*}{$\begin{array}{l}\text { Total } \\
\text { no. of } \\
\text { strains }\end{array}$} & \multicolumn{3}{|c|}{$\begin{array}{l}\text { CCIS System 1976-621-74346 } \\
\text { No. of strains: }\end{array}$} & \multicolumn{3}{|c|}{$\begin{array}{l}\text { CCIS System 1977-1432 } \\
\text { No. of strains: }\end{array}$} \\
\hline & & & $\begin{array}{l}\text { Correctly } \\
\text { identified }\end{array}$ & $\begin{array}{l}\text { Not } \\
\text { identified }\end{array}$ & $\begin{array}{l}\text { Incorrectly } \\
\text { identified }\end{array}$ & $\begin{array}{l}\text { Correctly } \\
\text { identified }\end{array}$ & $\begin{array}{l}\text { Not } \\
\text { identified }\end{array}$ & $\begin{array}{l}\text { Incorrectly } \\
\text { identified }\end{array}$ \\
\hline Achromobacter sp biotype 1 & A9112, C349, C675, C7259 & 4 & 1 & $\mathbf{0}$ & 3 & 3 & $\mathbf{0}$ & 1 \\
\hline Achromobacter sp biotype 2 & $\begin{array}{l}\text { D8708, D9035, D9053 } \\
\text { NCTC 10807* NCTC 10808, NCTC } 10809 \text {. }\end{array}$ & $\begin{array}{l}3 \\
5\end{array}$ & $\mathbf{0}$ & 0 & 3 & 0 & 1 & 2 \\
\hline Achromobacter xylosoxidans & $\begin{array}{l}\text { NCTC 10807*, NCTC 10808, NCTC 10809, } \\
\text { CL335/75, CL434/75 }\end{array}$ & & & & & & & \\
\hline Acinetobacter calcoaceticus & $\begin{array}{l}\text { NCTC 7250, NCTC 7363, NCTC } 7364 \text {, } \\
\text { NCTC 7412, NCTC 7844* }\end{array}$ & 5 & 5 & $\mathbf{0}$ & $\mathbf{0}$ & 5 & $\mathbf{0}$ & $\mathbf{0}$ \\
\hline Acinetobacter lwoffii & $\begin{array}{l}\text { NCTC 5866*, NCTC 5867, NCTC 7976, } \\
\text { E632, E871 }\end{array}$ & 5 & 5 & $\mathbf{0}$ & $\mathbf{0}$ & 5 & $\mathbf{0}$ & $\mathbf{0}$ \\
\hline Aeromonas hydrophila & $\begin{array}{l}\text { NCTC 7810, NCTC 7812, NCTC 8049*, } \\
\text { E232, E326 }\end{array}$ & 5 & 3 & 2 & $\mathbf{0}$ & 5 & $\mathbf{0}$ & $\mathbf{0}$ \\
\hline Alcaligenes odorans & $\begin{array}{l}\text { NCTC } 655, \text { NCTC } 10388, \text { NCTC } 10416 \text {, } \\
\text { CL98/73, CL158/73 }\end{array}$ & 5 & 3 & $\mathbf{0}$ & 2 & 4 & 0 & 1 \\
\hline Alcaligenes denitrificans & NCTC 8582 & 1 & $\mathbf{0}$ & $\mathbf{0}$ & 1 & 1 & $\mathbf{0}$ & $\mathbf{0}$ \\
\hline Alcaligenes faecalis & $\begin{array}{l}\text { NCTC 415*, NCTC 8764, NCIB 9387, } \\
\text { NCIB 9986, CL675/76 }\end{array}$ & 5 & 2 & 2 & 1 & 4 & 1 & $\mathbf{0}$ \\
\hline Bordetella bronchiseptica & $\begin{array}{l}\text { NCTC } 452^{*} \text {, NCTC } 454, \text { NCTC } 455 \text {, } \\
\text { NCTC } 456 \text {, NCTC } 458\end{array}$ & 5 & 5 & 0 & $\mathbf{0}$ & 5 & $\mathbf{0}$ & $\mathbf{0}$ \\
\hline Flavobacterium meningosepticum & NCTC 10016*, NCTC 10585, NCTC 10586 & 3 & 3 & $\mathbf{0}$ & $\mathbf{0}$ & 3 & $\mathbf{0}$ & $\mathbf{0}$ \\
\hline Flavobacterium group IIb & NCTC 10795, NCTC 10796, NCTC 10797 & 3 & 3 & $\mathbf{0}$ & $\mathbf{0}$ & 3 & $\mathbf{0}$ & $\mathbf{0}$ \\
\hline Flavobacterium group IIf & $\begin{array}{l}\text { NCTC 10798, NCTC } 10799, \text { NCTC } 10800 \text {, } \\
\text { CL112/67, CL172/69 }\end{array}$ & 5 & 4 & $\mathbf{0}$ & 1 & 1 & 3 & 1 \\
\hline Flavobacterium group IIj & B6306*, B9541 & 2 & $\mathbf{0}$ & $\mathbf{0}$ & 2 & 0 & $\mathbf{0}$ & 2 \\
\hline Pseudomonas paucimobilis & $\begin{array}{l}\text { NCTC } 11030^{*}, \text { NCTC } 11031, \text { NCTC } 11032 \text {, } \\
\text { CL173/70, CL135/72 }\end{array}$ & 5 & 1 & 4 & 0 & 5 & $\mathbf{0}$ & $\mathbf{0}$ \\
\hline Flavobacterium group IIk-2 & $\begin{array}{l}\text { NCTC 11033*, NCTC 11034, B9042, } \\
\text { D8510, D8864 }\end{array}$ & 5 & 2 & 1 & 2 & 2 & 1 & 2 \\
\hline Alcaligenes group IVe & C9573, D2312, D7460, D8817 & 4 & 3 & $\mathbf{0}$ & 1 & 3 & 1 & $\mathbf{0}$ \\
\hline Pseudomonas group Va-1 & B19 & 1 & $\mathbf{0}$ & $\mathbf{0}$ & 1 & 1 & 0 & $\mathbf{0}$ \\
\hline Pseudomonas group Va-2 & A5310, A8661 & 2 & 0 & $\mathbf{0}$ & 2 & 1 & $\mathbf{0}$ & 1 \\
\hline Pseudomonas pickettii & $230,279,286,288^{*}, 298$ & 5 & $\mathbf{0}$ & 1 & 4 & 2 & 1 & 2 \\
\hline Pseudomonas group Ve-1 & A7701*, B237, B1117, B5264 & 4 & 4 & 0 & $\mathbf{0}$ & 3 & 1 & $\mathbf{0}$ \\
\hline Pseudomonas group Ve-2 & B993*, B2524, B5066, B5142 & 4 & 4 & $\mathbf{0}$ & $\mathbf{0}$ & 3 & $\mathbf{0}$ & 1 \\
\hline Moraxella group M-4 & B9265, D7836, D8054, KC 1290 & 4 & 0 & $\mathbf{0}$ & 4 & $\mathbf{0}$ & $\mathbf{0}$ & 4 \\
\hline Flavobacterium odoratum & $\begin{array}{l}\text { NCTC } 11036^{*}, \text { CL607/74, CL103/75, } \\
\text { CL588/75, CL164/76 }\end{array}$ & 5 & 5 & $\mathbf{0}$ & 0 & $\mathbf{0}$ & 4 & 1 \\
\hline Moraxella bovis & NCTC $8561 *$, NCTC 9425 & 2 & 2 & $\mathbf{0}$ & 0 & 1 & 1 & $\mathbf{0}$ \\
\hline Moraxella lacunata & NCTC 7985, NCTC 7986 & 2 & 2 & 0 & $\mathbf{0}$ & 2 & $\mathbf{0}$ & $\mathbf{0}$ \\
\hline Moraxella liquefaciens & NCTC 7911, NCTC 10358 & 2 & 1 & 0 & 1 & 1 & 1 & $\mathbf{0}$ \\
\hline Moraxella nonliquefaciens & NCTC 7784, NCTC 10464 & 2 & 2 & 0 & 0 & 2 & 0 & 0 \\
\hline Moraxella osloensis & NCTC 10465, CL161/70 & 2 & 2 & 0 & $\mathbf{0}$ & 2 & 0 & $\mathbf{0}$ \\
\hline Moraxella phenylpyruvica & $\begin{array}{l}\text { NCTC 10526, CL157/67, CL113/69, } \\
\text { CL173/69, CL456/73 }\end{array}$ & 5 & 2 & 0 & 3 & 1 & 2 & 2 \\
\hline Pasteurella haemolytica & $\begin{array}{l}\text { NCTC } 9712, \text { NCTC } 10369 \text {, NCTC } 10370 \text {, } \\
\text { NCTC } 10609 \text {, NCTC } 10631\end{array}$ & 5 & 3 & $\mathbf{0}$ & 2 & 4 & $\mathbf{0}$ & 1 \\
\hline Pasteurella multocida & $\begin{array}{l}\text { NCTC } 3195^{\circ}, \text { NCTC } 5868, \text { NCTC } 8080 \text {, } \\
\text { NCTC 8282, NCTC } 10382\end{array}$ & 5 & 3 & $\mathbf{0}$ & 2 & 3 & $\mathbf{0}$ & 2 \\
\hline Pasteurella ureae & $\begin{array}{l}\text { NCTC } 10219 \text {, NCTC } 10220, \text { NCTC 10221, } \\
\text { NCTC } 10222, \text { CL576/76 }\end{array}$ & 5 & $\mathbf{0}$ & 0 & 5 & 5 & $\mathbf{0}$ & $\mathbf{0}$ \\
\hline Plesiomonas shigelloides & $\begin{array}{l}\text { NCTC 10360*, NCTC 10363, NCTC 10364, } \\
\text { E387, CL582/77 }\end{array}$ & 5 & 4 & 1 & $\mathbf{0}$ & 2 & 3 & $\mathbf{0}$ \\
\hline Pseudomonas aeruginosa & $\begin{array}{l}\text { NCTC 1999, NCTC } 2000 \text {, NCTC } 6750 \text {, } \\
\text { NCTC } 7244, \text { NCTC } 10332^{*}\end{array}$ & 5 & 5 & 0 & $\mathbf{0}$ & 5 & 0 & 0 \\
\hline Pseudomonas acidovorans & $\begin{array}{l}\text { NCTC 9991, NCTC 10683*, ATCC 17406, } \\
\text { CIP } 60.78, \text { CIP } 64.36\end{array}$ & 5 & $\mathbf{0}$ & 3 & 2 & 2 & 1 & 2 \\
\hline Pseudomonas alcaligenes & NCTC 10367* & 1 & 1 & $\mathbf{0}$ & $\mathbf{0}$ & 1 & $\mathbf{0}$ & 0 \\
\hline Pseudomonas cepacia & $\begin{array}{l}\text { NCTC 10661, NCTC 10734, NCTC 10743*, } \\
\text { NCTC 10744, CL37/70 }\end{array}$ & 5 & 1 & 2 & 2 & 4 & 0 & 1 \\
\hline $\begin{array}{l}\text { Pseudomonas diminuta } \\
\text { Pseudomonas fluorescens }\end{array}$ & $\begin{array}{l}\text { NCTC 8545*, AB236, AB265, AB328, AB359 } \\
\text { NCTC 3756, NCTC 10038*, NCTC 10392, } \\
\text { CL170/68, CL174/68 }\end{array}$ & $\begin{array}{l}5 \\
5\end{array}$ & $\begin{array}{l}4 \\
2\end{array}$ & $\begin{array}{l}\mathbf{0} \\
\mathbf{0}\end{array}$ & $\begin{array}{l}1 \\
3\end{array}$ & $\begin{array}{l}5 \\
2\end{array}$ & $\begin{array}{l}\mathbf{0} \\
\mathbf{0}\end{array}$ & $\begin{array}{l}\mathbf{0} \\
\mathbf{3}\end{array}$ \\
\hline Pseudomonas mallet & $\begin{array}{l}\text { NCTC 3708, NCTC } 3709 \text {, NCTC } 10229 \text {, } \\
\text { NCTC } 10230 \text {, NCTC } 10245\end{array}$ & 5 & $\mathbf{0}$ & 1 & 4 & $\mathbf{0}$ & 1 & 4 \\
\hline Pseudomonas maltophilia & $\begin{array}{l}\text { NCTC } 10257^{*} \text {, NCTC } 10258 \text {, NCTC } 10259 \text {, } \\
\text { NCTC } 10498 \text {, NCTC } 10499\end{array}$ & 5 & 4 & 1 & $\mathbf{0}$ & 4 & 0 & 1 \\
\hline Pseudomonas pseudoalcaligenes & $\begin{array}{l}\text { NCTC } 8769 \text {, NCTC } 10860^{*} \text {, ATCC } 17442, \\
\text { ATCC } 17443 \text {, NCIB } 9390\end{array}$ & 5 & 5 & $\mathbf{0}$ & $\mathbf{0}$ & 5 & $\mathbf{0}$ & $\mathbf{0}$ \\
\hline Pseudomonas pseudomallei & $\begin{array}{l}\text { NCTC } 1688 \text {, NCTC } 4845 \text {, NCTC } 4846 \text {, } \\
\text { NCTC } 6700 \text {, NCTC } 7383\end{array}$ & 5 & 3 & 1 & 1 & 1 & 1 & 3 \\
\hline
\end{tabular}

(Table cont. on following page) 
(cont. from previous page)

\begin{tabular}{|c|c|c|c|c|c|c|c|c|}
\hline \multirow[t]{2}{*}{ Taxon } & \multirow[t]{2}{*}{ Strains examined } & \multirow{2}{*}{$\begin{array}{l}\text { Total } \\
\text { no. of } \\
\text { strains }\end{array}$} & \multicolumn{3}{|c|}{$\begin{array}{l}\text { CCIS System 1976-62I-74346 } \\
\text { No. of strains: }\end{array}$} & \multicolumn{3}{|c|}{$\begin{array}{l}\text { CCIS System 1977-1432 } \\
\text { No. of strains: }\end{array}$} \\
\hline & & & $\begin{array}{l}\text { Correctly } \\
\text { identified }\end{array}$ & $\begin{array}{l}\text { Not } \\
\text { identified }\end{array}$ & $\begin{array}{l}\text { Incorrectly } \\
\text { identified }\end{array}$ & $\begin{array}{l}\text { Correctly } \\
\text { identified }\end{array}$ & $\begin{array}{l}\text { Not } \\
\text { identified }\end{array}$ & $\begin{array}{l}\text { Incorrectly } \\
\text { identified }\end{array}$ \\
\hline Pseudomonas putida & $\begin{array}{l}\text { NCTC 10936*, CL237/73, CL238/73, } \\
\text { CL239/73, CL240/73 }\end{array}$ & 5 & 5 & 0 & 0 & 5 & $\mathbf{0}$ & 0 \\
\hline Pseudomonas putrefaciens & $\begin{array}{l}\text { NCTC } 10735^{*}, \text { NCTC } 10737, \text { NCTC } 10738 \text {, } \\
\text { NCTC 10762, NCTC } 10763\end{array}$ & 5 & 2 & 3 & 0 & 2 & 3 & 0 \\
\hline Pseudomonas stutzeri & $\begin{array}{l}\text { NCTC 10450, NCTC 10473, NCTC 10475*, } \\
\text { CL142/73, CL 147/73 }\end{array}$ & 5 & 3 & 1 & 1 & 0 & $\mathbf{0}$ & 5 \\
\hline Pseudomonas mendocina & $\begin{array}{l}\text { NCTC } 10897, \text { NCTC 10898, NCTC } 10899 \text {, } \\
\text { CH34, CH35 }\end{array}$ & 5 & 0 & 0 & 5 & 0 & 0 & 5 \\
\hline Pseudomonas testosteroni & $\begin{array}{l}\text { NCTC 10698*, ATCC 17407, NCIB 8893, } \\
\text { NCIB 9682, NCIB } 9683\end{array}$ & 5 & 4 & $\mathbf{0}$ & 1 & 4 & $\mathbf{0}$ & 1 \\
\hline Pseudomonas vesicularis & $\begin{array}{l}\text { NCTC } 10900^{*}, \text { AB } 102, \text { AB } 794, \text { AB } 995 \text {, } \\
\text { AB } 1014\end{array}$ & 5 & 0 & 1 & 4 & 1 & 2 & 2 \\
\hline Vibrio alginolyticus & NCTC 10675 & 1 & $\mathbf{0}$ & 1 & $\mathbf{0}$ & $\mathbf{0}$ & 1 & $\mathbf{0}$ \\
\hline Vibrio cholerae & $\begin{array}{l}\text { NCTC } 5395 \text {, NCTC } 7254 \text {, NCTC } 7270 \text {, } \\
\text { NCTC } 8021 \text {, NCTC } 8457\end{array}$ & 5 & 4 & $\mathbf{0}$ & 1 & 4 & 0 & 1 \\
\hline Vibrio parahaemolyticus & $\begin{array}{l}\text { NCTC } 10441 \text {, NCTC } 10884 \text {, NCTC } 10885 \text {, } \\
\text { NCTC 10886, NCTC } 10903\end{array}$ & 5 & 0 & 1 & 4 & 2 & 2 & 1 \\
\hline \multirow[t]{2}{*}{ Chromobacterium violaceum } & $\begin{array}{l}\text { NCTC } 8683, \text { NCTC } 8684, \text { NCTC } 8685 \text {, } \\
\text { NCTC } 9370, \text { NCTC } 9757\end{array}$ & 5 & 5 & 0 & 0 & 5 & 0 & $\mathbf{0}$ \\
\hline & Totals: & 222 & $\begin{array}{l}125 \\
(56 \%)\end{array}$ & $\begin{array}{l}27 \\
(12 \%)\end{array}$ & $\begin{array}{l}70 \\
(32 \%)\end{array}$ & $\begin{array}{l}138 \\
(62 \%)\end{array}$ & $\begin{array}{l}31 \\
(14 \%)\end{array}$ & $\begin{array}{l}53 \\
(24 \%)\end{array}$ \\
\hline Bordetella parapertussis & $\begin{array}{l}\text { NCTC 5952, NCTC } 7385 \text {, NCTC } 8250 \text {, } \\
\text { NCTC } 10520 \text {, NCTC } 10521\end{array}$ & 5 & 0 & 0 & 5 & 0 & 0 & 5 \\
\hline Brucella spp & $\begin{array}{l}\text { NCTC 10084, NCTC 10094, NCTC } 10095 \text {, } \\
\text { NCTC 10096, NCTC } 10316\end{array}$ & 5 & 0 & $\mathbf{0}$ & 5 & $\mathbf{0}$ & 3 & 2 \\
\hline Chromobacterium lividum & $\begin{array}{l}\text { NCTC } 7150, \text { NCTC } 7917, \text { NCTC } 9796, \\
\text { NCTC 10646, E779 }\end{array}$ & 5 & $\mathbf{0}$ & 0 & 5 & $\mathbf{0}$ & 1 & 4 \\
\hline 'Pseudomonas thomasii' & $\begin{array}{l}\text { NCTC 10893, NCTC 10894, NCTC 10895, } \\
\text { CL21/70, CL283/70 }\end{array}$ & 5 & 0 & 0 & 5 & $1 \dagger$ & 0 & 4 \\
\hline
\end{tabular}

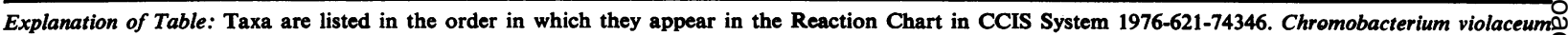

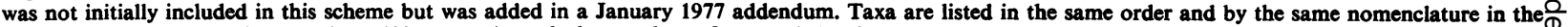

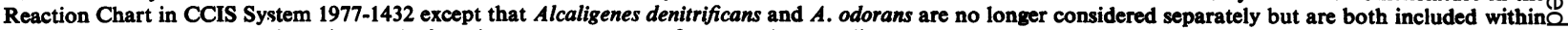

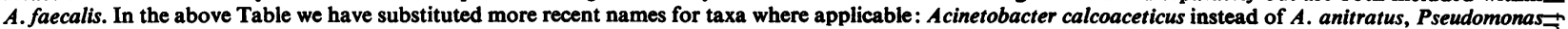

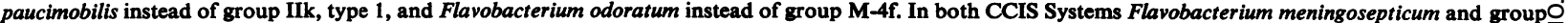

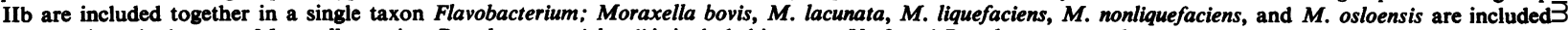

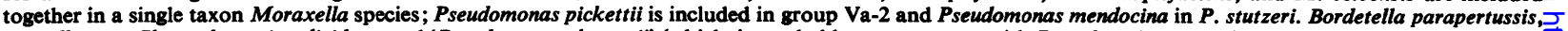

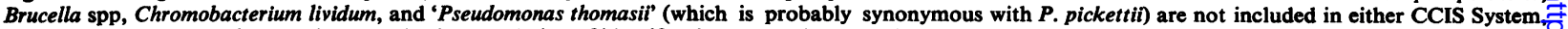

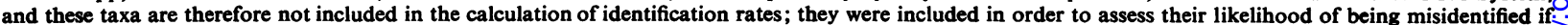
examined in the Oxi/Ferm Tube.

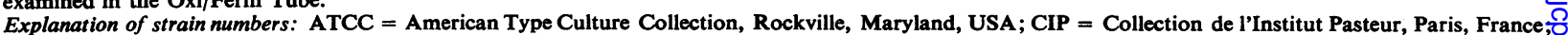

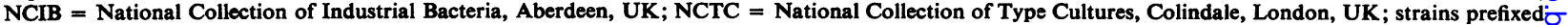

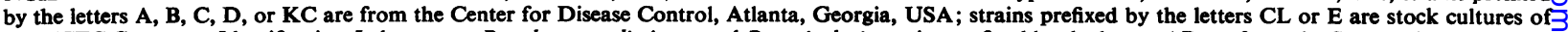

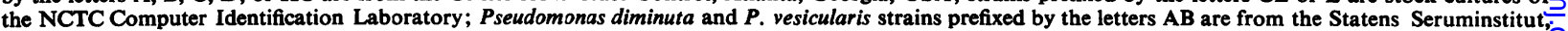

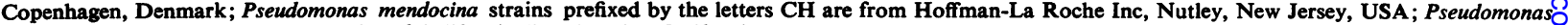
pickettii strains are from the University of California, Los Angeles, California, USA.

* Strain tested in Oxi/Ferm Tube in triplicate for assessment of reproducibility.

†Identified as group Va-2.

et al. (1977) also studied test reproducibility of this kit but did not publish their results.

\section{Material and methods}

\section{ORGANISMS}

Two hundred and forty-two strains were used to assess the success of the Oxi/Ferm Tube system in identification (Table), 222 of which represented all the 45 non-fermentative and nine oxidase-positive fermentative taxa included in the two identification systems so far produced by the manufacturer, one in 1976 and one in 1977. These strains comprised 188 reference strains (142 of which were from culture collections and 46 from reference experts) and 34 field strains referred to the National Collection of Type Cultures (NCTC) for computer-assisted identification; if type or neotype strains had been designated for a particular taxon then these were included.

The remaining 20 strains ( 17 culture collection and three field strains) represented four additional nonfermentative taxa not included in the two Oxi/Ferm Tube identification systems. These strains were, therefore, not used in the calculation of identification rates but were included in order to see whether they were likely to be misidentified.

Of the 242 strains, all the non-fermenters had been 
previously examined in at least the 68 characteristics described by Holmes et al. (1975) and their identity confirmed or determined by the computer identification method of Lapage et al. (1973) with the use of an unpublished probability matrix devised in the NCTC for non-fermenters. All the fermenters had been previously examined for 50 characteristics and their identity confirmed or determined by the computer identification method of Lapage et al. (1973) and probability matrix of Bascomb et al. (1973).

\section{TESTS AND METHODS}

All 242 strains were examined in the Roche Oxi/Ferm Tube, which consists of a plastic tube within which are compartments of test media in agar slopes, and contains the following nine tests: acid from dextrose under anaerobic conditions; production of arginine dihydrolase, nitrogen gas, hydrogen sulphide, and indole; acid from xylose and from dextrose under aerobic conditions; production of urease; and citrate utilisation. The oxidase test, performed conventionally, is used to supplement these nine tests so that the basic identification system consists of 10 tests.

In accordance with the manufacturer's instructions, the Oxi/Ferm Tubes were each inoculated with well isolated colonies from 24-hour cultures grown on nutrient agar. The media are inoculated by withdrawing a pre-sterilised inoculating wire (which is part of and inside the kit) through the compartments. The manufacturer states that the Oxi/Ferm Tube must be inoculated with a heavy inoculum, but when the inoculating wire is drawn through the Oxi/Ferm Tube it passes initially through an aperture of a diameter equal to that of the wire. As a result, no matter how large an inoculum is placed on the end of the wire, most bacterial growth is scraped off on passage through the aperture. With some of the more fastidious organisms, in particular, the expected positive reactions often could not be obtained with the Oxi/Ferm Tube, and no method was found to increase the inoculum size sufficiently to give the expected reactions.

The Oxi/Ferm Tubes were incubated at $37^{\circ} \mathrm{C}$ (as recommended by the manufacturer) for most strains, but with some species which prefer lower growth temperatures (for example, $\boldsymbol{P}$. fluorescens and $P$. putida) incubation at $30^{\circ} \mathrm{C}$ was necessary for the expected reactions to be obtained. Strains of Chromobacterium lividum were incubated at room temperature $\left(18-22^{\circ} \mathrm{C}\right)$, the highest temperature at which they grow.

The reactions obtained with the Oxi/Ferm Tube are recorded by comparison with a colour chart after $\mathbf{4 8}$ hours' incubation, except for the urease test, which is recorded at both 24 and 48 hours since 'rapid urea hydrolysis' is one of the additional tests that may be necessary for identification. Indole is the only test requiring the addition of a reagent, introduced by a needle and syringe through the plastic film covering the $\mathrm{H}_{2} \mathrm{~S}$ compartment. Although the manufacturer recommends that the reagent should be allowed to reach the agar surface, we found the test easier to interpret by introducing sufficient reagent to form a droplet on the underside of the plastic film that covers the test compartment. By rotating the tube from side to side, the development of a pink colour in the reagent droplet was easily discerned even when the reaction was only weakly positive.

IDENTIFICATION OF STRAINS

The reactions of the nine Oxi/Ferm Tube tests are recorded as a three-digit number based on octal numbers. The oxidase test result is used to form a fourth digit. This four-digit number is looked up in a register entitled Computer Coding and Identification System for < Oxi/Ferm Tube > Roche (CCIS System), of which two versions were produced during the course of this evaluation, the first 1976-621-74346 together with January 1977 addendum, and the second 1977-1432 (referred to in the following text as the 1976 and 1977 systems respectively). Most strains could not be adequately differentiated on the results of the basic $10 \mathrm{Oxi} /$ Ferm Tube tests and so it was necessary to carry out the additional conventional tests suggested in the register. The results of these additional tests were often available when the register was consulted either from reading of the Oxi/Ferm Tube itself (eg, rapid urea hydrolysis, alkaline reaction in xylose medium) or from a purity plate (eg, pigment, wrinkled colonies). In some cases, final identification was delayed until the results of further tests were available (eg, anaerobic growth, growth at $42^{\circ} \mathrm{C}$ ).

If the four-digit number derived from the reactions of a strain was listed in the identification register, together with the results of any additional tests required, an identification was considered 'correct' when the indicated taxon agreed with the identity of the strain and as 'incorrect' when they disagreed. Strains were considered 'not identified' when their four-digit number was not listed in the identification register, or when the number was listed but the results of the additional conventional tests prevented either correct identification or an incorrect identification.

For details, the reader is referred to the manufacturer's instructions, which give full details of the kit and additional conventional tests, how they are to be inoculated and incubated, and how interpreted. 


\section{REPRODUCIBILITY OF TESTS}

Thirty strains (Table), each representing a different taxon, were each tested three times in Oxi/Ferm Tubes so that each test (excluding the oxidase test, which is not performed in the kit) on each of the $\mathbf{3 0}$ strains was carried out three times. When the results were being recorded, all three Oxi/Ferm Tubes for each strain were compared so that the differences in test results were due to actual differences in the colours of the reactions and not to differences in interpretation.

A convenient way of expressing test reproducibility is the probability of erroneous test results (Sneath and Johnson, 1972). In the present study, each test was repeated three times, and for simplicity in presentation of the results it is assumed that if the three results were consistent $(+++$ or $\left.--_{-}\right)$then all three results were correct, and if the results were inconsistent $(\mathrm{eg},++-$ or --+$)$, the single minority result was an error. For the results of three replicate tests presented in this way an estimate of the probability of an erroneous test result, which is not biased by these assumptions, is given by $C$,

$$
C=\frac{1}{2}(1-\sqrt{1-4 E / N})
$$

where $E$ is the number of errors observed, $N$ is the total number of test results, and $C$ is termed the corrected error rate. This formula is obtained from formulae (4) and (14) of Sneath and Johnson (1972).

\section{Results}

\section{IDENTIFICATION OF STRAINS}

As can be seen from the Table, the 1977 system yielded a $6 \%$ improvement in identification rate over the 1976 system. The proportion of strains remaining not identified differed by only $2 \%$ between the two systems; however, use of the 1977 system decreased the rate of incorrect identification by $8 \%$. Although the overall identification rate for the 1977 system was only $62 \%$, the identification rate varied for individual taxa (Table) and was satisfactory for strains of Acinetobacter calcoaceticus, A. lwoffii, Aeromonas hydrophila, Bordetella bronchiseptica, Flavobacterium meningosepticum, Flavobacterium group IIb, Pseudomonas paucimobilis (group IIk, type 1; Holmes et al., 1977a), Pasteurella ureae, Pseudomonas aeruginosa, $P$. diminuta, $\boldsymbol{P}$. pseudoalcaligenes, $\boldsymbol{P}$. putida, and Chromobacterium violaceum, which include most of the non-fermentative species most frequently isolated from routine clinical material. For some taxa, the improvement in identification rate between the two systems was dramatic; for example, all the strains of Pasteurella ureae were incorrectly identified on the 1976 system but correctly identified on the 1977 system. For other taxa, the performance in identification was worse with the 1977 system; for example, all five strains of Flavobacterium odoratum (group M-4f; Holmes et al., 1977b) identified correctly on the 1976 system but four remained not identified and one was incorrectly identified on the 1977 system.

The Table shows that the strains of taxa not included in the identification systems were more likely to be incorrectly identified than to remain not identified.

REPRODUCIBILITY OF THE TESTS

The 30 strains were examined in triplicate in nine tests, giving a total of 810 test results. In 14 of the triplicates the results were inconsistent, that is, there were 14 errors and hence the corrected error rate was $1.8 \%$ with a $95 \%$ confidence interval $0.9 \%-2 \cdot 7 \%$.

\section{Discussion}

Despite its name, the Computer Coding and Identification System for < Oxi/Ferm Tube > Roche is a register of patterns of results, and no use is made of probabilistic or any other method of computerassisted identification, as is also the case with the Encise System originally used with the Enterotube, but unlike the more recently devised system for Enterotube and that for the API 20E, both of which are computer-assisted, a strategy that increases the identification rate (Holmes et al., 1977c). Not unexpectedly, therefore, the identification rate of $62 \%$ with $24 \%$ incorrectly identified found for the Oxi/Ferm Tube using the 1977 system is similar to that obtained with the Enterotube using the Encise System $(70 \%$ correctly identified, $29 \%$ incorrectly identified; Holmes et al., 1977c). The low identification rate found for the Oxi/Ferm Tube is due partly to the small number of tests employed (10 basic and a maximum of nine additional in the 1977 system) and partly to the lack of computer-assisted identification. Identification rates of $85-90 \%$ have been achieved in the NCTC for non-fermentative bacteria using a probability matrix based on 68 tests and computer assistance. Completion of the matrix may improve performance and enable us to publish it.

Difficulties in evaluating and comparing both different test kits and the results obtained with kits by various authors have been discussed by Holmes et al. (1978). In our evaluation of the Oxi/Ferm Tube, we examined more taxa than the routine laboratory is likely to encounter, and as the strains chosen do not reflect their distribution in routine clinical 
material, the identification rate we obtained cannot be applied directly to clinical practice. Our results indicate that the Oxi/Ferm Tube 1977 system might be expected to give a better performance in the clinical laboratory than the identification rate of $62 \%$ achieved in our study, as identification was better with many of the commoner taxa likely to be found in clinical material. This is borne out by the identification rates of $84 \%$ to $98 \%$ found by various authors who evaluated the kit in clinical laboratories, or in special studies using smaller numbers of the commoner taxa (not exceeding 33 and often less than 20 compared to the 54 used in our study). Smith et al. (1978) tested the Oxi/Ferm Tube with cultures of rarely encountered organisms and obtained identification rates of around $50 \%$. Such evaluations must be treated with caution because to check identifications obtained from kits, the identity of the strains must be known on independent criteria, and this is not always done, or the criteria used, which must be stringent, are not stated satisfactorily. Conventional tests and schemes for the identification of non-fermenters have been developed only in recent years and are not yet widely used, at least to our knowledge in the UK, so the established identities in evaluation in clinical laboratories must be carefully inspected.

For comparison of kit identifications, the particular identification systems (manufacturer's number, date, etc) used must be known, and precise comparison can be made only between evaluations using the same system; less accurate comparisons may, however, still have some validity, for example, the $6 \%$ gain in identification of the 1977 over the 1976 system may still allow some comparison if one laboratory used the earlier and the other the later system.

Details in the publication may be inadequate to ascertain the use of the same system: for example, Oberhofer et al. (1977b) used for the Oxi/Ferm Tube an 'original' and then a 'revised' manual. These may or may not correspond respectively to our 1976 system (CCIS 1976-621-74346) and 1977 system (1977-1432), as Oberhofer et al. (1977b) stated rather ambiguously: 'Eleven strains of Alcaligenes odorans were correctly identified using the original code, whereas no code was provided in the revised manual'. In CCIS System 1977-1432, A. odorans was included in $\boldsymbol{A}$. faecalis.

The differentiation of the alkali-producing pseudomonads is particularly difficult, and although in the 1976 system the register contained identification to species level, in the 1977 version these pseudomonads were grouped together with the misleading title 'Pseudomonas species', misleading since $\boldsymbol{P}$. aeruginosa, for example, was a separate taxon, and if a strain of this species identified as 'Pseudomonas species' then it should be considered an incorrect identification. Oberhofer et al. (1977b) also noted this combination of species and did not consider 'Pseudomonas species' sufficiently precise to constitute an entirely accurate identification, which illustrates the confusion in kit comparison when one kit identifies the species and another a genus or a group of species. Oberhofer et al. (1977b) also appeared in their evaluation to have considered 'Pseudomonas species' at genus level identification to include all pseudomonads not just the alkaliproducers. With such pitfalls, it seems simplest to consider a strain to be correctly identified when its known identity corresponds to a taxon defined by the manufacturer as containing the species to which that strain belongs, irrespective of whether the identification is to species, genus, or some other level.

The probability of erroneous test results for the Oxi/Ferm Tube of $1.8 \%$ is near the typical range of $2 \%-4 \%$ for the average probability of errors for conventional biochemical tests within a single laboratory certainly to be expected with the potential central quality control of kits. Isenberg and SampsonScherer (1977) found the Oxi/Ferm Tube gave results with a better level of reproducibility than we found; from their results we estimated a probability of erroneous test results of $0.7 \%$ (cf our value of $1.8 \%$ ). From the results of McHale et al. (1978) we estimate a probability of errors of $4 \%$ for the citrate and urea tests and $2.5 \%$ or less for other tests. Other reports on test reproducibility do not define how 'reproducibility' was calculated and so estimates of the probabilities of errors cannot be obtained from the results quoted. The probability of errors between laboratories for conventional tests is typically $6 \%-10 \%$ on average (Holmes et al., 1977c). Provided that interpretation schemes for kit tests are accurate and sophisticated, it should be possible to obtain a level of reproducibility between laboratories using the same kit within the range obtained in a single laboratory using conventional tests. The Oxi/Ferm Tube tests were fairly easy to read but the colour chart provided by the manufacturer was not considered to be very realistic, and the chart could be improved to aid in the interpretation of weak or doubtful reactions.

The Oxi/Ferm Tube was developed from the Enterotube and therefore possesses the advantages and disadvantages of the latter kit; both are speedily inoculated, and even a Bunsen burner is not necessary. However, the manufacturer recommends that the indole reagent should be added to the indole test compartment by means of a syringe and needle. This could prove dangerous should the needle 
come into contact with pathogens in the compartment and the needle subsequently accidentally puncture the skin of the user. If the indole compartment cannot be modified so as to obviate the use of a needle for addition of the reagent, then the manufacturer might also consider recommending that the reagent be introduced as a droplet just under the transparent film covering the compartment and reading the result there instead of allowing the reagent to reach the agar surface of the medium.

The manufacturer recommends inoculation of the Oxi/Ferm Tube with a heavy suspension yet, because of the design of the tube (see Material and methods), the inoculum cannot be increased beyond a certain amount, and may be inadequate to give the expected results with certain fastidious organisms. Possibly widening the aperture through which the inoculum is drawn might enable adequate inoculum to be used. It should be recommended that the tubes are incubated, not at $37^{\circ} \mathrm{C}$ for all organisms, but at the optimum growth temperature of the strain being tested, since some of the strains we tested, eg, Pseudomonas fluorescens, failed to give the expected reactions unless incubated at $30^{\circ} \mathrm{C}$. The user should also be instructed to examine the urea compartment of the tube at 24 hours in case rapid urea hydrolysis proves to be one of the necessary additional tests. Finally, since the 20 strains of the four taxa not included in the calculation of identification rates tended to be incorrectly identified rather than remain not identified, the manufacturer might at least take account of these taxa in the compilation of future data bases, even if they are not directly included in the identification scheme.

Our results suggest that, to improve the identification rate, the number of tests may need to be increased, or the number of taxa reduced, retaining only those taxa most commonly found in clinical material, and placing emphasis on those additional tests that prevent strains belonging to taxa not included in the identification scheme from being incorrectly identified into included taxa.

Although the results were available, we have not compared for each strain the test results obtained in the Oxi/Ferm Tube with the test results obtained in the corresponding conventional tests. We consider that such a comparison has little scientific merit since, in considering different identification systems, it is not the comparability of individual test results that is important but the equivalence of the final identifications.

We are grateful to Roche Products Limited for the gift of Oxi/Ferm Tubes, which made this study possible. We are also indebted to $H$. Lautrop,
N. J. Palleroni, M. J. Pickett, and R. E. Weaver for the supply of certain reference cultures.

\section{References}

Bannister, E. R., West, M. E., Buchner, P. A., Alexander, M. M., and Manos, J. P. (1978). A comparison of three commercial systems for the identification of non-fermentative bacteria. Abstracts of the Annual Meeting of the American Society for Microbiology, p. 303.

Bascomb, S., Lapage, S. P., Curtis, M. A., and Willcox W. R. (1973). Identification of bacteria by computer: identification of reference strains. Journal of General Microbiology, 77, 291-315.

Dowda, H. (1977). Evaluation of two rapid methods for identification of commonly encountered nonfermenting or oxidase-positive, Gram-negative rods. Journal of Clinical Microbiology, 6, 605-609.

Freundlich, L. F., Rosenthal, S. L., and Washington, W. (1977). Clinical evaluation of the OXI/FERM Tube. Abstracts of the Annual Meeting of the American Society for Microbiology, p. 49.

Holmes, B., Lapage, S. P., and Malnick, H. (1975). Strains of Pseudomonas putrefaciens from clinical material. Journal of Clinical Pathology, 28, 149-155.

Holmes, B., Owen, R. J., Evans, A., Malnick, H., and Willcox, W. R. (1977a). Pseudomonas paucimobilis, a new species isolated from human clinical specimens, the hospital environment, and other sources. International Journal of Systematic Bacteriology, 27, 133-146.

Holmes, B., Snell, J. J. S., and Lapage, S. P. (1977b). Revised description, from clinical isolates, of Flavobacterium odoratum Stutzer and Kwaschnina 1929, and designation of the neotype strain. International Journal of Systematic Bacteriology, 27, 330-336.

Holmes, B., Willcox, W. R., and Lapage, S. P. (1978). Identification of Enterobacteriaceae by the API $20 \mathrm{E}$ system. Journal of Clinical Pathology, 31, 22-30.

Holmes, B., Willcox, W. R., Lapage, S. P., and Malnick, H. (1977c). Test reproducibility of the API (20E), Enterotube, and Pathotec systems. Journal of Clinical Pathology, 30, 381-387.

Isenberg, H. D., and Sampson-Scherer, J. (1977). Clinical laboratory evaluation of a system approach to the recognition of nonfermentative or oxidaseproducing Gram-negative, rod-shaped bacteria. Journal of Clinical Microbiology, 5, 336-340.

Killbourn, J. P. (1977). Oxi-Ferm TM system (Letter). American Journal of Medical Technology, 43, 1167-1168.

Lapage, S. P., Bascomb, S., Willcox, W. R., and Curtis, M. A. (1973). Identification of bacteria by computer: general aspects and perspectives. Journal of General Microbiology, 77, 273-290.

McHale, K. M., Teplitz, M. G., and Gavan, T. L. (1978). Reproducibility of organism "ID values" determined by the Oxi/Ferm Tube system. Abstracts of the Annual Meeting of the American Society for Microbiology, p. 304.

Nadler, H., George, H., and Barr, J. (1978). Comparison of the Oxi/Ferm ${ }^{\mathrm{R}}$ system to a conventional methods 
for bacterial identification. Abstracts of the Annual Meeting of the American Society for Microbiology, p. 290.

Nord, C.-E., Wretlind, B., and Dahlbäck, A. (1977). Evaluation of two test-kits-API and Oxi Ferm Tubefor identification of Oxidative-Fermentative Gramnegative rods. Medical Microbiology and Immunology, 163, 93-97.

Oberhofer, T. R., Rowen, J. W., Cunningham, G. F., and Higbee, J. W. (1977a). Evaluation of the Oxi/ Ferm TM Tube system with selected Gram negative bacteria. Abstracts of the Annual Meeting of the American Society for Microbiology, p. 49.

Oberhofer, T. R., Rowen, J. W., Cunningham, G. F., and Higbee, J. W. (1977b). Evaluation of the Oxi/Ferm tube system with selected Gram-negative bacteria. Journal of Clinical Microbiology, 6, 559-566.

Otto, L. A., Aspin, M. M., and Blachman, U. (1978). Nonfermentative bacilli: Evaluation of four systems for identification. Abstracts of the Annual Meeting of the American Society for Microbiology, p. 303.

Rinehart, S. L., and Oberhofer, T. R. (1978). A compari- son of the API 20-E and Oxiferm systems to a conventional method in the identification of nonfermentative bacteria. Abstracts of the Annual Meeting of the American Society for Microbiology, p. 303.

Smith, P. B., Hill, E. O., and Isenberg, H. D. (1978). Challenge of the Oxi/Ferm Tube with "difficult" and rarely encountered organisms. Abstracts of the Annual Meeting of the American Society for Microbiology, p. 304.

Sneath, P. H. A., and Johnson, R. (1972). The influence on numerical taxonomic similarities of errors in microbiological tests. Journal of General Microbiology, 72, 377-392.

Snyder, J., Vincent, S., Hoyng, C., Hankey, B., and Weaver, R. (1978). Comparison of three methods for the identification of nonfermentative bacilli. Abstracts of the Annual Meeting of the American Society for Microbiology, p. 304.

Timm, J. A., Hall, M. K., and Washington, J. A. (1978). Evaluation of the Oxi/Ferm Tube for identifying nonfermenters. Abstracts of the Annual Meeting of the American Society for Microbiology, p. 303. 